\title{
Organoids as a New In Vitro Model of Human Norovirus Infection
}

\section{Je Hyoung Kim, Young-II Jeong*}

Division of Viral Disease Research, Center for Infectious Diseases Research, National Institute of Health, Korea Centers for Disease Control and Prevention, Osong 28159, Republic of Korea

\author{
Corresponding \\ Young-Il Jeong, Ph.D. \\ Division of Viral Disease Research, \\ Center for Infectious Disease Research, \\ Korea National Institute of Health, \\ 187-ro, Osong-yeup, Cheongju, \\ Chungbuk, 28159, Republic of Korea \\ Phone : +82-43-719-8418 \\ Fax : +82-43-719-8459 \\ E-mail : woojusun012@korea.kr
}

Received : September 2, 2020

Revised : September 16, 2020

Accepted : September 18, 2020

No potential conflict of interest relevant to this article was reported.

Copyright (C) 2020 Journal of Bacteriology and Virology

(C) This is an Open Access article distributed under the terms of the Creative Commons Attribution Non-Commercial

License

(http://creativecommons.org/

license/by-nc/3.0/).
Human noroviruses (HuNoVs) are the main causative viral agents in epidemic and endemic acute gastroenteritis worldwide. Despite their impact on the global economic and health burden, developing effective control measures to prevent and treat norovirus gastroenteritis remains a difficult problem to solve. One of the major reasons for this problem is the lack of affordable small animal models and a robust and reproducible in vitro cell culture system for the propagation of this poorly characterized RNA virus. Recently, the development of a 3-dimensional culture system using pluripotent stem cells to mimic the native small intestine has led to the discovery of new strategies for the cultivation of this virus. In this review, we describe a human stem cell-derived intestinal organoid model that led to the development of the currently available HuNoV in vitro culture systems that support replication of the virus, and provide helpful insights into HuNoV biology and vaccine and therapeutic development.

Key Words: Human noroviruses, Human intestinal enteroids, Human intestinal organoids

\section{INTRODUCTION}

Acute gastroenteritis is caused by various etiological agents, including viruses, bacteria, and parasitic protozoa; however, among these, acute gastroenteritis is most frequently caused by viruses (1). Together with rotavirus, human norovirus (HuNoV) is the main causative viral agent in epidemic and endemic acute gastroenteritis globally (2). Norovirus was previously called the Norwalk virus and was first identified in an outbreak of gastroenteritis in Norwalk, Ohio, USA in 1968. Noroviruses are non-enveloped, positive-sense, single-stranded RNA viruses that belong to the family Caliciviridae. Their viral genome consists of approximately 7.5-7.7. kb, which are organized into 3 open reading frames (ORFs) (ORF1, ORF2, and ORF3). There is significant genetic diversity among noroviruses owing to specific mutations and genetic recombination. Based on major and minor differences in the genetic sequence, the norovirus genus is subdivided into 10 genogroups (GI-GX) $(3,4)$. Currently, 41 genotypes belonging to 3 genogroups (GI, GII, GIII and GIV) have been associated with acute gastroenteritis in humans (5). HuNoVs are highly contagious viruses that cause vomiting and diarrhea within 24-48 hour (h) of the incubation period. These viruses can pass through the fecal-oral route by direct person-to-person contact or through feces-contaminated food or water (6). Although the infection is 
self-limiting within a few days, viral shedding continues in the feces for the next few weeks in immunocompromised patients (6). Susceptibility to norovirus infection at all ages leads to high rates of hospitalization and mortality. Therefore, norovirus gastroenteritis is recognized as a considerable societal and economic burden worldwide. Children under the age of 5 years, adults older than 65 years, and immunocompromised individuals are particularly vulnerable and more likely to develop severe disease. In children $<5$ years of age, there are currently more than 50,000 norovirus-associated deaths annually (7).

Despite the global burden of human norovirus infections on the economy and healthcare, developing effective control measures to prevent and treat norovirus gastroenteritis remains a challenge. Over the past several decades, despite many attempts to solve these problems, no fundamental changes have been made to date. The lack of an affordable small animal model and a robust and reproducible in vitro cell culture system for HuNoV propagation has been a significant obstacle for the successful development of live attenuated vaccines for this poorly characterized RNA virus. In particular, to understand the HuNoV-host interaction that underlies the high virus infectivity and volatile illness, it is necessary to develop an in vitro culture system. Therefore, developing a robust and reproducible culture system for HuNoV propagation can help to identify ways to prevent the transmission and treat infection and illness. Since the discovery of the Norwalk virus in 1972, many experiments toward the development of a cultivation system for HuNoV in vitro propagation have been performed using typical simple transformed cell lines. However, most of these laboratory efforts have not produced highly satisfactory results (8-12). Therefore, up to now, the development of multigenerational passaging systems of HuNoVs remain as a conundrum to be solved. However, struggles to cultivate this virus in vitro eventually led to the development of new strategies for HuNoV in vitro culture. These include the development of an infection-and-replication model using either primary stem cells or pluripotent stem cells to better mimic the native small intestine. This strategy is also called 'organoid technology', which bridges the gap between conventional two-dimensional cell line culture and the in vivo model. Cultivation of microorganisms in human intestinal organoid models has led to a new era for studying infectious diseases, such as those caused by noroviruses. Various intestinal infectious disease processes have been modeled using stem cell-derived organoids. Recently, it has been shown that many infectious pathogens can infect organoids, including parasites, rotavirus, enterohemorrhagic Escherichia coli, and Salmonella (13). In this review, we describe the key advances that led to the development of the currently available HuNoV in vitro culture systems that support replication of the virus.

\section{New challenges in the development of human norovirus culture system using stem cell-derived intestinal organoids}

Organoids are 3-dimensional structures derived from self-organizing pluripotent stem cells. Organoid formation is similar to organism development from a zygote that gives rise to a mature adult organism. Thus, employing the signaling pathways that control organ development in vivo, pluripotent stem cells can be differentiated into different cell types and grown ex vivo as organoid models. This process includes precisely controlled differentiation, proliferation, and apoptosis paired with multicellular self-organization and patterning, which leads to diverse mature tissues (14). Organoid formation can be derived from three types of human pluripotent stem cells, and each stem cell is different: embryonic stem cells (ESCs) are isolated from a blastocyte. Induced pluripotent stem cells (iPSCs) are reprogrammed from adult tissues, and adult stem cells (ASCs) are isolated from mature tissues. Therefore, because organoids are derived from these human-based stem cells, they provide the genetic and physiological similarity and the complex in vivo environment required for the enhanced modeling of human disease, in comparison to current animal models and simple transformed cell lines. In addition, unlike many primary tissue models, organoids are long-lived and can be passaged as well as frozen for later use $(15,16)$. Recent advances in organoid culture technology have enabled precise analysis of the in vivo architecture, functionality, and genetic signature of various original tissues. Therefore, using multiple engineering strategies, organoids are currently employed in a variety of research applications with extensive studies and data, including infectious disease, drug discovery and screening, toxicology, and regenerative medicine. 


\section{Current organoid models for studying human norovirus}

The human natural intestinal epithelium consists of enterocytes, goblet cells, enteroendocrine cells, microfold cells (or M cells), and Paneth cells. Each cell is newly generated in the crypt and is lost by apoptosis at the tips of the villi. These cells are generated from self-renewing stem cells present in the intestinal crypt bottom and build crypt-villus structures. It has recently been shown that Lgr5-positive stem cells, which are isolated from intestinal crypts, could generate all cell types of the epithelium in vitro without a mesenchymal niche (17). Because stem cell-derived intestinal organoids recapitulate many components of the original organ in vivo, they present a suitable model for studying the interaction between the gastrointestinal tract and enteric viruses. There are two different types of human intestinal models according to stem cell type: human intestinal enteroids (HIEs) and induced human intestinal organoids (HIOs) (Fig. 1). HIOs are derived from iPSCs or embryonic PSCs, whereas HIEs are generated from intestinal stem cells (cycling crypt base columnar cells and quiescent stem cells) isolated from the intestinal crypt region (Table 1). Both HIEs and HIOs can display the architecture and functionality of the native human intestinal as well as the near-physiologic cellular composition and behaviors. Recently, three types of organoids originating from different stem cells have emerged as effective infection models to build improved systems for studying enteric viruses, including HuNoV and human rotavirus (HRV), due to their closeness in emulating the infected organs.

\section{Human intestinal organoids (HIOs) model originating from embryonic stem cells}

Together with HuNoV, HRV is also a major cause of severe gastrointestinal illness worldwide. The growth of this gastrointestinal virus is limited in most transformed cell lines and animal models. However, the development of the stem cell-derived induced HIOs model opened a new avenue for HRV research. The first attempt at culturing human gastrointestinal viruses in three-dimensional organotypic models has been pioneered by Mary K. Este's group using HIOs. They demonstrated that induced HIOs could support rotavirus replication on the basis of detection of nonstructural viral proteins, increased levels of viral RNA, and production of infectious progeny viruses (18).

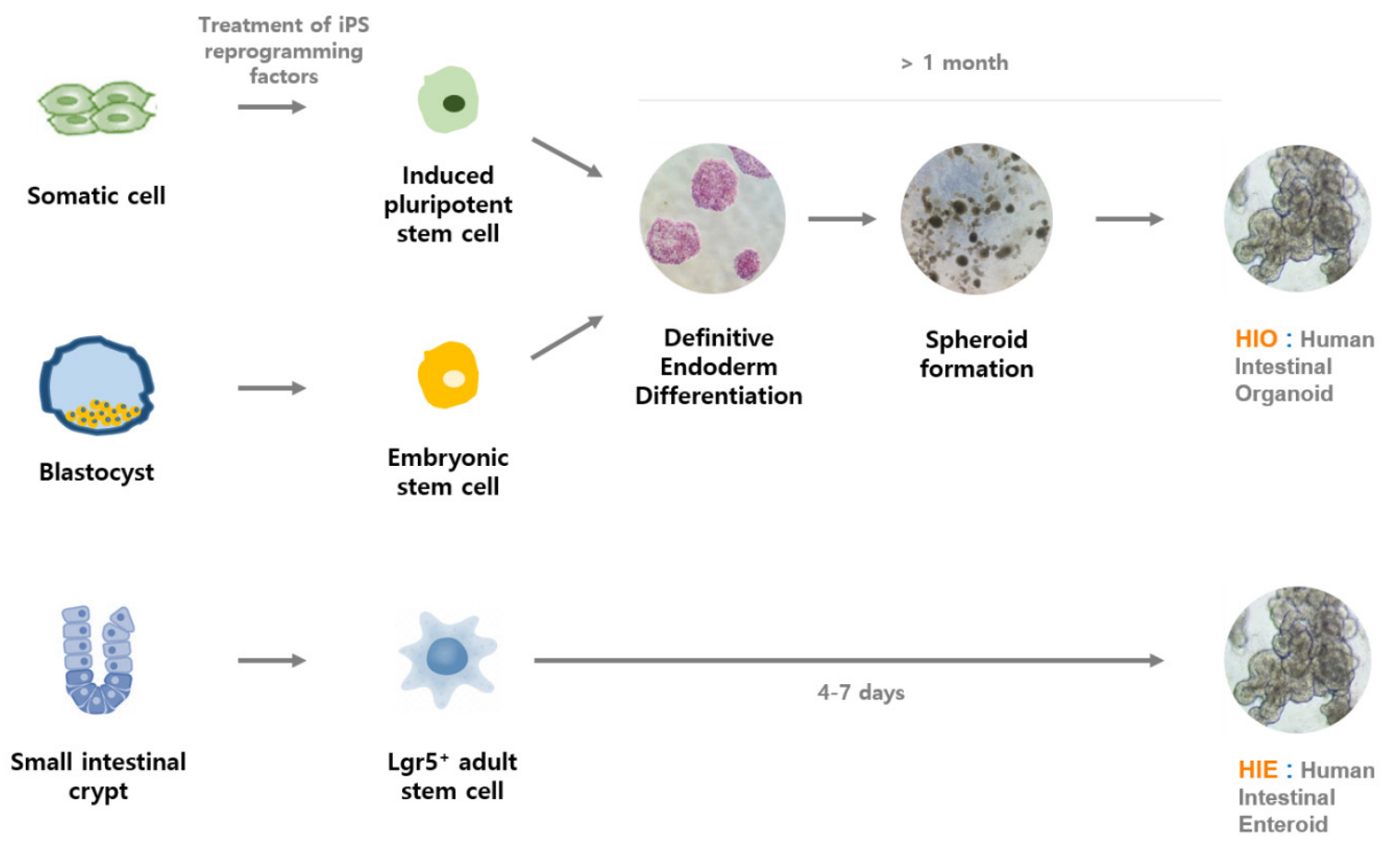

Fig. 1. Comparison between the culture process and features of HIOs and HIEs. 
Based on the recent success of HRV replication in HIOs, there has been an initial attempt to replicate HuNoVs in the HIO model originating from embryonic stem cells. A recent study yielded promising results on the potential usefulness of HIOs for studying the HuNoV replication mechanism (19). In this study, two HIOs lines that represent secretor-positive and secretor-negative status were successfully established, and their histoblood group antigen (HBGA) expression and specific interactions with several huNoV-virus-like particles (HuNoV-VLPs) were characterized. HuNoV replication in HIOs derived from embryonic stem cells was also supported by 10 passages of the original inoculum in fresh HIOs.

However, while HIEs can be easily cultured using stem cells isolated from the intestinal crypt, the development of the HIO model from embryonic stem cells necessitates a long process because it requires more induction steps involving more growth factors than HIEs. In addition, a weakness of the embryonic PSC-derived HIO model is that it provides a limited amount of HuNoV progeny compared to HIE. This may be due to the very limited numbers of differentiated enterocytes in $\mathrm{HIOs}$ and the effects of $\mathrm{HIO}$ maturity or differentiation level compared to enterocytes in HIEs. Nevertheless, embryonic stem cell-derived HIOs may provide a useful tool for understanding the developmentally regulated dynamics of HBGA expression, which are known to be age-regulated in humans and may further affect the host susceptibility to HBGA-recognized pathogens, such as noroviruses and rotaviruses (20). Xi Jiang group found that various types 1 and 2 HBGAs are fully expressed in fully developed HIOs. And they also confirmed that these HBGAs contain ewis, secretor, and nonsecretor antigens, distributing on the glycocalyx and selected huNoV-like particles bind the glycocalyx of HIOs with matched HBGA phenotypes (19).

\section{Human intestinal epithelial cells (IECS) model originated from iPSCs}

Most recently, the induced PSC-derived intestinal epithelial cell (IEC) model established by Sato's group was suggested as a valuable model for HuNoV recapitulation (21). IECs were prepared as monolayer cells for HuNoV inoculation by disrupting iPSC-derived intestinal organoids cultured in Matrigel. In this culture system, IECs could be invaded and subsequently used as sites of replication for the GII.3, GII.4, GII.6, and GII.17 genotypes of HuNoV without bile requirement, in contrast to the results of a previous study (Table 1) (22) Interestingly, Sato's group demonstrated in this IEC model that anti-GII.17 pAb suppressed the replication of GIl.4 HuNoV, even though anti-GII.4 pAb was unable to block the replication of other genotypes of GII HuNoVs. Therefore, the cross-reactivity of antibodies in blocking other genotypes in the same genogroup as HuNoVs suggests their potential as multivalent vaccine antigens for HuNoV. In addition, because the IECs model is derived from human iPSCs, there are fewer ethical concerns than the HIE model that involves human biopsy and surgical tissue. Through these results, the iPSC-derived IECs model is considered to be a useful tool for industrial applications, including the evaluation of vaccine candidates and antibody immune responses in clinical trials.

Table 1. Summary of 3 type of human intestinal organoid models for studying human norovirus infection

\begin{tabular}{|c|c|c|c|c|c|c|c|}
\hline Author (year) & Infection model & Stem cell sauce & $\begin{array}{l}\text { Genotype identified } \\
\text { with productive } \\
\text { replication }\end{array}$ & Bile requirement & Multiple passages & $\begin{array}{l}2 \mathrm{D} / 3 \mathrm{D} \text { culture } \\
\text { for infection }\end{array}$ & $\begin{array}{c}\text { Cytopathic effect } \\
\text { (CPE) }\end{array}$ \\
\hline Ettayebi et al. (2016) & $\begin{array}{l}\text { HIEs generated } \\
\text { from stem cells } \\
\text { of human } \\
\text { intestinal crypts }\end{array}$ & $\begin{array}{l}\text { Stem cells isolated from } \\
\text { intestinal crypts in } \\
\text { human intestinal tissues }\end{array}$ & $\begin{array}{l}\text { GI.1, GII.3, GII.4, } \\
\text { and GII.17 }\end{array}$ & $\begin{array}{c}\text { GII.3, GII.17 and } \\
\text { GI.1 HuNoVs; } \\
\text { Not GII.4 } \\
\text { HuNoVs }\end{array}$ & $\begin{array}{l}4 \text { passages from the } \\
\text { original GII. } 4 \text { huNoVs } \\
\text { inoculum }\end{array}$ & $\begin{array}{l}\text { Jejunal enteroid } \\
\text { monolayers }\end{array}$ & $\begin{array}{c}\text { cell rounding, } \\
\text { destruction of the } \\
\text { monolayer and an } \\
\text { increase in number of } \\
\text { dead cells }\end{array}$ \\
\hline Zhang et al. (2017) & $\begin{array}{l}\text { HIOs developed } \\
\text { from human } \\
\text { embryonic PSC }\end{array}$ & $\begin{array}{l}\text { Embryonic PSC line } \\
\text { WA01(non-secretor) and } \\
\text { WA09(secretor) }\end{array}$ & $\begin{array}{l}\text { GI.1, GII.4, GII.9, } \\
\text { and GII.21 }\end{array}$ & - & $\begin{array}{l}10 \text { passages from the } \\
\text { original GII. } 4 \text { huNoVs } \\
\text { inoculum }\end{array}$ & HIOs & - \\
\hline Sato et al. (2017) & $\begin{array}{l}\text { IECs developed } \\
\text { from human } \\
\text { iPSC }\end{array}$ & $\begin{array}{l}\text { human induced } \\
\text { pluripotent stem cell } \\
\text { (iPSC) line (TkDN4-M1) }\end{array}$ & $\begin{array}{l}\text { GII.3, GII.4, GII.6, } \\
\text { and GII.17 }\end{array}$ & $\begin{array}{c}\text { GII.3, GII.4, GII.6, } \\
\text { and GII.17 could } \\
\text { replicate in human } \\
\text { primary IECs } \\
\text { without bile } \\
\text { supplementation }\end{array}$ & $\begin{array}{l}3 \text { passages from the } \\
\text { original GII. } 4 \text { huNoVs } \\
\text { inoculum }\end{array}$ & $\begin{array}{l}\text { Well-polarized } \\
\text { monolayers of } \\
\text { IECs }\end{array}$ & - \\
\hline
\end{tabular}




\section{HIE model originating from iPSCs}

As seen in recently published papers by Mary K. Este's group, HIEs and other new models for understanding human gastrointestinal viral host-pathogen interactions have also been used. They successfully supported the replication of HuNoV and $\operatorname{HRV}(22,23)$. However, unlike rotavirus replication, observed in the enterocytes and enteroendocrine cells of HIEs, various HuNoV strains have only been detected in enterocytes $(23,24)$. In addition, through this improved culture system, it was identified that some HuNoV strains require the presence of bile for their replication (22). Gll.4 variants exhibited a productive and complete virus replication cycle in this culture system without bile supplementation, while the GI.1, Gll.3, and GII.17 HuNoV strains failed to replicate in the absence of exogenously added bile (22). It is known that the effect or role of bile acid in HuNoV replication is on the cells and not on the virus. X-ray crystallography has shown that bile acids bind to partially conserved pockets on the $P$ domain of some genotypes and stabilize the $P$ domain loops in HBGA non-binders (25)

In addition, using the HIE culture system, it was demonstrated that the secretor status of HIEs affects strain-specific HuNoV replication (22). Many human challenge and outbreak studies have suggested that HuNoV infection is dependent on the presence of HBGAs, which is known as a genetic factor that determines host susceptibility. Secretor status regulated by fucosyltransferase 2 (FUT2), which transfers fucose to HBGA precursors in gastrointestinal cells, has been proposed to mediate susceptibility to infection with most Gll.4 HuNoVs (26). HIE models generated from secretor-positive sources support productive replication of both Gll.4 and GII.3 HuNoV variants (22). However, in HIEs generated from secretor-negative individuals, the Gll.4 strain could not infect, and Gll.3 viruses were partially infective (22). The Mary K. Este group also showed that the HIE cultivation system allows the evaluation of virus neutralization and inactivation. The above results suggest that the HIE model is a useful new method to measure the effectiveness of disinfectants and sanitizers $(22,27)$. Passaging HIE-infected HuNoV is possible, but sustained passaging is limited to several passages. Therefore, it remains to be improved in the future.

\section{CLOSING REMARKS}

HuNoV remains a difficult problem to solve globally. The availability of the classical infection models, including various 2-D cultures of immortalized cells and animal models, has not produced highly satisfactory results with regard to the understanding of how pathogens modulate host functions during infection and the development of successful live attenuated vaccines. Clearly, organoid technology has facilitated studies to understand the interactions between the gastrointestinal tract and enteric viruses and has proven to be a good model for the replication of non-cultivable viruses, such as the norovirus. Despite the progress in the development of the HuNoV culture systems, the field still faces several challenges that need to be solved in order to further enhance these culture systems, including the expense and complexity of culture media and lack of sustained passaging of the HuNoV strains. And also, Low viral replication yields and reproducibility and labor intensive process is problems to be solved. Fortunately, biological and bioengineering solutions are being developed at a rapid pace to solve these problems. Compared with two-dimensional cultures, three-dimensional organoid culture systems can provide more fundamental insights into the pathogenesis of HuNoV and may further enhance new translational approaches for the treatment and prevention of this enteric virus.

\section{ACKNOWLEDGMENTS}

This research was supported by a research program funded by the Korea Centers for Disease Control and Prevention (Grant Number: 2019-NI069-00). 


\section{REFERENCES}

1) Graves NS. Acute gastroenteritis. Prim care 2013;40:727-41.

2) Ahmed SM, Hall AJ, Robinson AE, Verhoef L, Premkumar P, Parashar UD, et al. Global prevalence of norovirus in cases of gastroenteritis: a systematic review and meta-analysis. Lancet Infect Dis 2014;14:725-30.

3) Thorne LG, Goodfellow IG. Norovirus gene expression and replication. J Gge Viro/2014;95:278-91.

4) Todd KV, Tripp RA. Human Norovirus: Experimental Models of Infection. Viruses 2019:11:151.

5) Vinjé J. Advances in laboratory methods for detection and typing of norovirus. J Clin Microbio/2015:53:373-81.

6) Devasia T, Lopman B, Leon J, Handel A. Association of host, agent and environment characteristics and the duration of incubation and symptomatic periods of norovirus gastroenteritis. Epidemiollnfect 2015:143:2308-14.

7) Shah MP, Hall AJ. Norovirus Illnesses in Children and Adolescents. Infect Dis Clin North Am 2018:32:103-18.

8) Duizer E, Schwab KJ, Neill FH, Atmar RL, Koopmans MPG, Estes MK. Laboratory efforts to cultivate noroviruses. J Gen Viro/2004;85:79-87.

9) Straub TM, Höner zu Bentrup K, Orosz-Coghlan P, Dohnalkova A, Mayer BK, Bartholomew RA, et al. In vitro cell culture infectivity assay for human noroviruses. Emerg Infect Dis 2007:13:396-403.

10) Herbst-Kralovetz MM, Radtke AL, Lay MK, Hjelm BE, Bolick AN, Sarker SS, et al. Lack of norovirus replication and histo-blood group antigen expression in 3-dimensional intestinal epithelial cells. Emerg Infect Dis 2013;19:431-8.

11) Papafragkou E, Hewitt J, Park GW, Greening G, Vinjé J. Challenges of culturing human norovirus in three-dimensional organoid intestinal cell culture models. PloS one 2013:8:e63485.

12) Takanashi S, Saif LJ, Hughes JH, Meulia T, Jung K, Scheuer KA, et al. Failure of propagation of human norovirus in intestinal epithelial cells with microvilli grown in three-dimensional cultures. Arch Viro/2014;159:257-66.

13) Zhang YG, Wu S, Xia Y, Sun J. Salmonella-infected crypt-derived intestinal organoid culture system for host-bacterial interactions. Physiol Rep 2014;2:e12147.

14) Yin X, Mead BE, Safaee H, Langer R, Karp JM, Levy O. Engineering Stem Cell Organoids. Cell Stem Cell 2016:18:25-38.

15) Foulke-Abel J, In J, Kovbasnjuk O, Zachos NC, Ettayebi K, Blutt SE, et al. Human enteroids as an ex-vivo model of host-pathogen interactions in the gastrointestinal tract. Exp Biol Med 2014;239:1124-34.

16) Leushacke M, Barker N. Ex vivo culture of the intestinal epithelium: strategies and applications. Gut 2014;63:1345-54.

17) Sato $T$, Vries RG, Snippert HJ, van de Wetering $M$, Barker $N$, Stange $D E$, et al. Single Lgr5 stem cells build crypt-villus structures in vitro without a mesenchymal niche. Nature 2009;459:262-5.

18) Finkbeiner SR, Zeng XL, Utama B, Atmar RL, Shroyer NF, Estes MK. Stem cell-derived human intestinal organoids as an infection model for rotaviruses. mBio 2012;3:e00159-12.

19) Zhang $D$, Tan $M$, Zhong $W$, Xia $M$, Huang $P$, Jiang $X$. Human intestinal organoids express histo-blood group antigens, bind norovirus VLPs, and support limited norovirus replication. Sci Rep 2017:7:12621.

20) Etzold S, Bode L. Glycan-dependent viral infection in infants and the role of human milk oligosaccharides. Curr Opin Virol2014;7:101-7. 
21) Sato S, Hisaie K, Kurokawa S, Suzuki A, Sakon N, Uchida Y, et al. Human Norovirus Propagation in Human Induced Pluripotent Stem Cell-Derived Intestinal Epithelial Cells. Cell Mol Gastroenterol Hepato/2019;7:686-8 e5.

22) Ettayebi K, Crawford SE, Murakami K, Broughman JR, Karandikar U, Tenge VR, et al. Replication of human noroviruses in stem cell-derived human enteroids. Science 2016:353:1387-93.

23) Saxena K, Blutt SE, Ettayebi K, Zeng XL, Broughman JR, Crawford SE, et al. Human Intestinal Enteroids: a New Model To Study Human Rotavirus Infection, Host Restriction, and Pathophysiology. J Viro/2015:90:43-56.

24) Chang-Graham AL, Danhof HA, Engevik MA, Tomaro-Duchesneau C, Karandikar UC, Estes MK, et al. Human Intestinal Enteroids With Inducible Neurogenin-3 Expression as a Novel Model of Gut Hormone Secretion. Cell Mol Gastroenterol Hepato/ 2019;8:209-29.

25) Kilic T, Koromyslova A, Hansman GS. Structural Basis for Human Norovirus Capsid Binding to Bile Acids. J Virol 2019;93:e01581-18.

26) Ruvoën-Clouet N, Belliot G, Pendu JL. Noroviruses and histo-blood groups: the impact of common host genetic polymorphisms on virus transmission and evolution. Rev Med Viro/2013:23:355-66.

27) Costantini V, Morantz EK, Browne H, Ettayebi K, Zeng XL, Atmar RL, et al. Human Norovirus Replication in Human Intestinal Enteroids as Model to Evaluate Virus Inactivation. Emerg Infect Dis 2018;24:1453-64. 